\title{
Valuation of Flexibility
}

\author{
Sushil
}

Received: 6 May 2015/Accepted: 6 May 2015/Published online: 20 May 2015

(C) Global Institute of Flexible Systems Management 2015

The need for enhancing flexibility at various levels in the enterprise has been emphasized (over time) both in literature and practice, in view of the growing uncertainty and turbulence in carrying out the business. Various antecedents of flexibility (and their impact on it) have been identified and empirically tested in past researches. At the same time, implementation of different flexibility practices in different aspects of the enterprise has also been observed and reported. Numerous researchers and practitioners have espoused the cause of flexibility and deliberated on the need to have flexibility in modern day organizations. The impact of flexibility on organizational performance has also been highlighted to some extent. But the valuation of flexibility at strategic level has not been addressed commensurate to the felt need and real life practice of flexibility.

It would be worthwhile to create a valuation model for assessing the strategic value gained by enhancing flexibility in enterprises. Some valuation models have been developed in past in the areas of financial flexibility, manufacturing flexibility, and information systems flexibility. But valuation models of strategic flexibility are comparatively rare. Some early developments on the front of strategic flexibility (coping with unforeseen circumstances) have taken into consideration reduction in the impact of environmental changes on one hand, and increase in response capacity on the other; which later got evolved into managing paradox (continuity and change) on the continuum (Eppink 1978; Sushil, 2015a). It has also been

\section{Sushil $(\square)$}

Department of Management Studies, Indian Institute of

Technology Delhi, Vishwakarma Bhawan, Shaheed Jeet Singh

Marg, New Delhi 110016, India

e-mail: sushil@dms.iitd.ac.in; profsushil@gmail.com linked to the vitality (survival and growth) and sustainability of the organization (Sushil 2011). On one hand, we intend to get better achievement of strategic goals by flexibility interventions, whereas these interventions would invariably be associated with some cost inputs on the other.

The strategic goals could be in terms of revenue, profitability, satisfaction of customers, employees and other stakeholders, societal benefits, risk, environment, quality, efficiency, and so on. The flexibility initiatives of different kinds would aid in achieving one or many of these strategic goals through fulfillment of the needs of uncertainty, variability, choice, speed, and so on, and this provides benefits to the organizations on multiple fronts. At the same time, these flexibility initiatives would demand capability building costs such as labour, process, technology, material and opportunity costs. In addition, there could be other costs such as difficulty of practicing it in real life, cognitive overload, and increase in system complexity. The benefits as well as the costs of flexibility would be both tangible and intangible.

Some significant representative benefits that could be derived by introducing flexibility initiatives may be in terms of capturing new opportunities, generating new ideas and innovations, opening new revenue sources, hedging risks, reducing process cost and time (by minimizing waste), anytime/anywhere reach, stakeholder involvement, and societal benefits (such as inclusion). In addition, specific benefits associated with select flexibility initiatives could be projected such as improving quality (from a customers' view point) by customization of products/services, extracting value by dynamic pricing, meeting variable demand with creation of flexible capacity, reducing manpower costs and meeting unforeseen job requirements through multiskilling, and higher employee satisfaction and involvement by flexible work design. Some specific areas 
where additional costs would be incurred to implement different flexibility initiatives are additional training required, implementation of new technology, increased costs of process and product design/development, restructuring to suit new initiatives, costs of change management, and requirements of higher working capital, among others.

The assessment of benefits associated with flexibility would be a measure of its worth, whereas examining it in relation with the additional cost defines its value or affordability. If the ratio of worth to cost of flexibility is more than one it could be treated as affordable and value generating, whereas if this ratio is less than one the flexibility initiative does not seem to be affordable at present. However, even if the ratio of tangible worth to tangible cost is less than one, it may be worthwhile to experiment it for long-term value creation, in case of its potential for fulfilling crucial strategic goals such as social inclusion and anytime reach.

In general, it is easy to assess the value of 'flexibility to use' any system rather than 'flexibility to change' the system in future. In case of fast changing technologies such as ICT (information and communication technology), it would be more viable to create systems that are flexible to use rather than having flexibility to change in terms of anticipated or unanticipated future changes that might take place, as the technology might become obsolete. On the other hand, for systems or entities having longer life such as buildings, it would be appropriate to incorporate 'flexibility to change' at the design stage, or else the cost of future changes could be very high in contrast to the initial additional cost of flexibility.

Let us take a couple of flexibility initiatives and carry out their valuation in terms of benefits and associated costs to understand the relevance of the proposed framework. For example, creating variable capacity to meet fluctuating demand pattern would generate benefits in terms of low inventory, generation of more revenue by meeting higher demand with the same system, and reducing the risk of over or under capacity (in case of fixed capacity design). At the same time, the variable capacity systems would entail higher initial costs of change in technology (used in manufacturing companies such as Toyota, Honda, etc.). Another way of meeting uncertain requirements is through flexibility initiative of multiskilling that would enable the organization to handle unprecedented job requirements at lower manpower costs, but certainly this would be associated with higher training costs of employees on multiple skills. This is very common in project based IT organizations (such as IBM, Infosys, TCS) that may get new types of projects with different combinations of skills. A popular flexibility initiative is in terms of flexi-time and flexi-place, which provides the benefits of employee empowerment/ involvement and work-life balance. This requires more coordination capabilities and job allocation and assessment complexities that can be met through technological interventions, thereby having more technological costs. These kinds of flexibility practices are common place in knowledge intensive organizations such as consulting, health, education, and so on.

The valuation of flexibility can be done in multiple ways. Firstly, it can be done as a 'go-no-go' decision, i.e. whether the proposed flexibility initiative is affordable or not. Secondly, if there is a felt need for flexibility in some area, it needs to be valued for the extent of flexibility desired, as with the increase of flexibility intensity the affordability may go high up to an extent due to increasing rate of return, but beyond a level the costs of providing flexibility may become prohibitive. Thirdly, the valuation of flexibility can be done over time, as the costs of providing flexibility may be higher initially, but the benefits may be generated over a period of time. Thus, the valuation or affordability needs to be assessed on a life cycle basis. Lastly, the valuation may be done to compare two or more flexibility initiatives to meet certain flexibility needs by assessing their affordability in a comparative sense using multi-criteria ranking methods. The valuation of flexibility may also be linked to the flexibility maturity model (Sushil $2012,2015 b)$. The value created by initiatives taken at different flexibility maturity levels can be separately assessed. It can also be applied to assess the value creation by flexibility initiatives across the value chain.

The above discussion provides a bird's eye view of valuation of flexibility giving its broad conceptual framework, manifestations, and the scope of its implementation. This indicates towards the need to develop empirically tested valuation models of various types of flexibility so as to make a pragmatic decision about taking affordable and value creating flexibility initiatives at various levels in the organizations.

\section{References}

Eppink, D. J. (1978). Planning for strategic flexibility. Long Range Planning, 11(4), 9-15.

Sushil, (2011). Flexibility, vitality and sustainability. Global Journal of Flexible Systems Management, 12(1\&2), iii.

Sushil, (2012). Flexibility maturity model: Possibilities and Directions. Global Journal of Flexible Systems Management, 13(2), $75-76$.

Sushil, (2015a). Strategic flexibility: The evolving paradigm of strategic management. Global Journal of Flexible Systems Management, 16(2), 113-114.

Sushil, (2015b). Managing Flexibility: Developing a Framework of Flexibility Maturity Model. In Sushil, K. T. Bhal \& S. P. Singh (Eds.), Managing flexibility: People, process, technology and business. Flexible Systems Management. New Delhi: Springer. 